\title{
Dissemination Does Not Equal Public Engagement
}

\author{
Bobby Heagerty \\ Neuroscience Community Affairs \& Education, OHSU (Oregon Health \& Science University) Brain Institute, Portland, Oregon 97239
}

\section{What}

Engaging key decision-makers in your research-namely, potential funders, elected officials, donors, community leaders, advocacy organizations, potential students, patients, and the general public-is more crucial than ever.

Only 31\% of Americans believe scientists communicate the impact of science effectively, according to recent poll data from Research!America, which prompted founder/executive director, Mary Wooley, to declare, "this finding should serve as a wake-up call. We can't rely on science to speak for itself; it's something we have to give a face and a voice to. If science stays invisible to the public, we can't expect the public's continuing support" (Wooley, 2014a). Additionally, Alan Alda recently asked, "How are scientists going to get money from policy makers if our leaders and legislators can't understand what they do?" (Dreifus, 2014). John Holdren, Director of the White House Office of Science and Technology Policy, echoed these concerns in testimony to Congress on February 27, 2014, "The Interagency Working Group on Neuroscience (IWGN) recently released a report identifying challenges and proposing recommendations in each of five areas of research, policy and communication:. . . 5) and improving communication and engaging the public. One of five priorities.

Public engagement is clearly a necessity. Talking to the public (some thinkers claim "talking at the public" is more accurate)_dissemination-is not the same thing as engaging the public. Dissemination goes one way; as information flows from those who are knowledgeable to

Received Oct. 6, 2014; revised Jan. 12, 2015; accepted Jan. 21, 2015.

Correspondence should be addressed to Bobby Heagerty, Director, Neuroscience Community Affairs \& Education, OHSU Brain Institute, 3181 SW Sam Jackson Park Road CR120, Portland, OR 97239. E-mail: Heagerty@ohsu.edu.

DOI:10.1523/JNEUROSCI.4408-15.2015

Copyright $\odot 2015$ the authors $\quad 0270-6474 / 15 / 354483-04 \$ 15.00 / 0$ those who are not. We need to change the language as well as the approach. NIH, the Defense Advanced Research Projects Agency (DARPA), the National Science Foundation (NSF), and other national entities fund research. Congress funds NIH, DARPA, NSF, and other agencies. The public elects congress. Therefore, neuroscientists should have a professional interest in engaging the public. The syllogism is accurate.

As Francis Collins recently asserted, "It is not just the science but the transmission of science; it's public engagement, not public relations" (Collins, 2013). To secure this point, it's also not simply teaching about neuroscience; it's conversing about neuroscience. It's the creation of an ongoing dialogue that, by definition, goes both ways. This model recognizes and honors the listener/learner (instead of speaking down) and creates a more organically effective connection-one that can be built upon. The speaker interested in public engagement is sympathetic, analytical, and adaptive, as opposed to superior, doctrinarian, and inflexible. The goal is to become an eloquent listener, to hear and understand what is being said. As Alan Leshner, chief executive of AAAS, so eloquently states, "We need to move beyond a paternalistic stance. Scientists seeking to engage non-scientific audiences should know before whom they stand. . You are speaking to them, not to yourself. Engagement requires warmth and it needs to be clear we respect our audience" (Leshner, 2003; Hosler, 2013).

Since the very ethos of science is to share and to build, using the following foundational values enables the science community to look beyond more traditional less effective means of communication.

\section{Why Should We Do This?}

Ideals established by and through these public engagement reforms:
1. Social accountability-Explain how our research helps the public - why it matters. Carol Mason recently said that as recipients of taxpayer funds, we have a responsibility to do so.

2. Trust and transparency-Show the human side of neuroscience.

3. Access and reciprocity-Encourage public engagement in direction of research.

4. Science literacy - Counteract "dumbing down"; keep focus on the program and away from fear-provoking notions and sweeping claims; prevent public backlash and funding freezes.

5. Public health-Improve self-care, parenting, healthy aging, good policy development, and environmental health.

6. Research advocacy-Advocate for the contextual research enterprise-and all that it entails (e.g., stem cell and animal research).

7. Translation-Interpret the impact; disseminate knowledge and discuss implications. . say why it's important; don't "bury the punchline"; become knowledge and application brokers.

8. Excitement-Enthuse and recruit the next generation of scientists.

9. Satisfy curiosity-Answer questions and stimulate more interest in the mysteries of the brain; neuroplasticity is an exciting phenomenon at all ages.

10. Make a difference-Know you have had an impact and enjoy the social interaction, the "high" from audience participation.

\section{When Should We Do This?}

Timing is everything. And now is the perfect time to engage the public. Everyone has a brain-and worries about it - and neuroscience is perceived as neither accessible nor user-friendly. The Age Wave is currently peaking at 65 and there are more people this age than people older or younger. One in three 65-year-olds will get Alzheimer's disease. "There is one rea- 
son elected officials and those running for office should pay attention to research," Mary Wooley recently said, "Alzheimer's Disease" (Wooley, 2014b). This huge group of boomers-the most do-ers and decision-makers in the country-is the group to engage. There is no better time than right now, to capitalize on logic and emotion.

We are also at the beginning of a multiyear focus on brain research. Effectively activating the public reciprocally bolsters efforts to position the United States at a global level as we seek international neuroscience research collaborations. We could and should lead in global advocacy for brain research.

\section{How Can We Do This?}

My experience can provide some answers.

In my own professional capacity, I have worked in neuroscience education and outreach program development-for both professional and community audiences-for 35 years. Early on, I helped start the Alzheimer's and Parkinson's Associations in Oregon. I purposefully developed strong political relationships from the beginning. Senator Ron Wyden aided me in starting the Alzheimer's Association; Senator Mark Hatfield brought in early support and energy to start the Alzheimer's Disease Center at Oregon Health \& Science University. More recently-in part as a result of a Brain Awareness public lecture he gave at Oregon Health \& Science University-Congressman Earl Blumenauer founded the Congressional Neuroscience Caucus to focus national attention on the importance of neuroscience research. In addition to my ongoing commitment to the Congressional Neuroscience Caucus and Congressman Blumenauer, I am assisting Congresswoman Suzanne Bonamici with her STEM to STEAM Caucus by sharing information on how the arts benefit the brain. I continue to engage these Representatives by providing both content and connections; but even more importantly, I help them to reach large numbers of voters and supporters through my constituencies and to identify with brain research in a very mutually beneficial way. The maintenance of these important political networks at a personal level is an often unseen and underappreciated aspect of engagement.

I have developed and sustained strong community partnerships with school districts; colleges and universities; teachers' organizations; non-profits such as the Oregon Museum of Science and Industry, Oregon Public Broadcasting, the Chil- dren's Institute, the Oregon Symphony, the Oregon Ballet Theater, the Pacific Northwest College of Art; and certain businesses that align with our mission, such as Powell's Books. Through political connections and community partners, I have developed many mechanisms to reach large numbers of individuals and find out about what they want to knownot just tell them what I (and we) think they should know. This focus on constituency development-building a community-is an investment in engagement.

Our Brain Awareness "Season," now 17 years old, has evolved from a small series of activities at our local museum of science and industry (OMSI) to several months' worth of events. These include a major downtown lecture series (which draws nationally known neuroscientists); a Teacher Workshop that each year fills our auditorium and is simulcast to four other regional locations; the annual SfN Oregon Chapter Symposium; a Neuroscience Town Hall featuring elected officials and a wide assortment of neuro-related advocacy organizations; and a Brain Fair in which over a hundred enthusiastic neuroscientists and thousands of children and families participate. Every person who attends one of these events or activities becomes part of the constituency (and willingly gets on the mailing list).

What I have learned over the years is that there are very important basic principles of public engagement-specific mechanisms that are essential to planning such programs, and ways that I, uniquely, can provide them. I provide insight into the learning process because I, myself-as a non-scientist_am learning constantly, and I pay attention to how learning happens best. I can therefore help teach scientists how to translate their science to other non-scientists. One starts where the learner is, builds trust, then takes him or her to the next level of engagement/involvement. That is what David Brooks, noted columnist, has called becoming a "thought leader."

To keep this information useful and manageable, I have framed each of these three contextual levels-Principles, Program, and Personal in easier-to-remember "Top Ten" lists.

\section{Understand the Basic Principles of Public Engagement}

1. Alignment - Be an effective "lazy susan"; develop connections that are both horizontal (collaborating with others involved in the same content/issues) and vertical (from grass-roots to policy-leaders).
2. Start right-Begin where the learner is, not where you are (match); empathize (pace); then, and only then, can you lead. Show your enthusiasm from the beginning.

3. Build good relationships-You can build anything on a good relationship; you can't build anything on a bad or nonexistent one. Reach out to advocacy organizations. They truly own the issue, be part of them-honor them. Help them with their voice and they will help you with yours.

4. Leverage-Use clout; who listens to whom (have that person-or those people-standing behind you, figuratively; i.e., "we feel that..."); cross-fertilize. Build a tapestry of influence; know when/ how to use it wisely.

5. Build a constituency-Create a following-this is your currency. Build an internal and an external community; gather names wherever you go; stay connected over time and build a sustained relationship. (I have 242 PIs, 935 neuroscience faculty/staff, a $6000+$ email list, $28,000+$ direct mail list. . . all ever growing.)

6. Communicate regularly-Utilize meetings, newsletters, events, and social media. Realize you suffer from the affliction "the curse of knowledge" by the sheer nature of your background. Clarify and simplify; always make sure the essence comes across. And openness to dialogue is a credibility-building must.

7. Satisfy-Meet a public need; leave them with insights that will change their lives, make them think, and inspire them to tell others.

8. Resonate-Connect science to society and to each individual's world; they are not separate. No "spinach journalism" (i.e., just because it's good for you). Contextualize how it fits within a bigger picture (science is the R\&D of the health care industry and essential for the public good).

9. Tap curiosity-Make it interesting and fun-not scary and obscure. Build upon current fascinations. Take the time to make your words ring.

10. Lead collaboratively-Weave a tapestry of ideas, groups, and individuals. Find ways to connect them all, and build trust. Inspire them with an attitude of "it's do-able, it's worth it, and I'll be with you in case you need help." Be a thought leader. See connections many can't-or don't-take the time to look for. Give context to help evaluate events or trends. Your value is determined by how much thought you generate in the audience you choose to engage. Be larger than the sum of your parts. 


\section{Develop a Brain Awareness Program}

Here are my top ten practical tips for developing a public engagement effort (evolved from an earlier version I presented at $\mathrm{SfN}$ ten years ago):

1. Start planning early and develop a team and a timeline; evaluate each year; cultivate a "friends" group that will help to connect with the community (they often become donors); consider developing a "brain campaign."

2. Select a good venue. Your venue should be accessible, with easy parking and a central location; adaptable; share in your vision and be able to provide in-kind contributions such as PR. And keep using it-make your event an exciting annual destination that the community anticipates each year.

3. Make it easy for the media to cover. Evolve with the changing scene- - use social media and cross-marketing with community partners to drive people to your website wherever you can.

4. Don't forget your internal marketing. Never stop selling. Link with other development and marketing efforts, including the foundation's donor development, the hospital's patient marketing, subject recruitment for clinical studies, student recruitment for the education program, and the communications/grants programs of research administration. Capture names wherever you go; have a free monthly e-newsletter that builds the relationship.

5. Develop classy, catchy materials and link marketing strategies; use novelty and unique angles - get attention (with goodies like chocolate brains and 3D brain images). Use pictures and graphics to show how everything fits. Innovate; create a brand.

6. Build lasting win/win community partnerships. The truth is, all groups can benefit from associating with neuroscience experts - arts, education, aging, parenting, advocacy organizations, and others-and you can benefit from reaching new audiences through them. Be opportunistic, not linear.

7. Focus on the translation factor rather than the dissemination factor; recruit an excellent science communicator as host/facilitator; build an ongoing dia$\log$ with Q/A and feedback forms for new ideas.

8. Link marketing strategies; your public will hear about this at least three times before they act.

9. Build on natural perceptions and themes-personal, local, and national (both fears and excitement). Cable TV, social media, and the tabloid press tend to favor sensationalism over context. This can distort the trust and play on emotion. By communicating directly with constituents this can be counteracted. Beginning with what's in the public interest instead of what's in one's private interest is a smart way to start and makes sure what one is saying resonates with the audience one needs to influence. Note: Specific ways to do this that have proven effective include taking advantage of existing excellent resources from the Society for Neuroscience's website and the Dana Alliance for Brain Initiatives for program and topic ideas.

10. Keep it fun; treat it as a celebration of the brain. . for presenters, participants, volunteers, attendees, donors. Recognize, praise, listen, thank, and provide refreshments.

\section{Tell your own Brain Story}

1. Be very clear-make one, three (best), or five points. Put yourself into the shoes of your target audience and frame what you say so it anticipates and answers their questions and explains why they should care; if an elected official, talk about numbers (human impact), dollars (economic impact), and their own voters who care (issues impact).

2. Choose a focus or topic that is perceived as "the latest" or "the cutting edge."

3. Engage the audience from the beginning - ask questions early on (like "How many of you. ...?").

4. Use mnemonic devices-Top Ten Tips, acronyms, symbols. Have them tell you at the end what (one, three, or five things) they learned.

5. Identify your compelling hooks (novelty, grabbers, a memorable twist of phrase, magnetic headlines). Then frame the issue; ask the question they might ask. Remember the basic tenets taught by cognitive neuroscience-first novelty, then attention, then learning, and, finally, memory.

6. Decide on your own best technique(s)—narrative, participation, mystery, informality, playfulness, spontaneity, personality, emotionality, comedy, surprise-don't take yourself too seriously.

7. The first impression should be about them, the listener, not you or "it" (the science); start with their interest not yours; people want their problems (basic or bizarre) solved; help by supplying them with solutions or pointers. Find out what excites the listener or most worries them. . .then start there.

8. A story has a beginning, a middle, and an end; stories are a tried-and-true way for people to absorb complex information, put it into context, and coat it with a positive feeling. It will help them remember what they hear and be able to agree with the conclusion.

9. Use action verbs and simple sentences; the fewer and stronger the words, the better. Use metaphors and similes to get their attention and help them visualize what you're talking about. Beware of the word "complex"; it basically implies the listener won't get it and is much overused. Don't qualify your message so much you don't get anything across; don't bury the punchline. And don't say "we just need more research"; your information, understanding and insight can make a difference right now.

10. Finally, if possible, have someone with you who can answer medical questions after the scientific aspect of the talk. There will always be those questions and there is always some information that can help. This also reinforces the fact the neuroscience is both basic science and clinical application.

\section{Summary}

Good Brain Awareness activities are happening across the country. These local efforts could align with national efforts in a more strategic way. If we encouraged and connected public engagement centers, we would get "neuroscience out now." This is an issue because, historically, neuroscientists have always talked about the hope for the cure or the search for the molecule that could someday make a difference. That excites scientists, but not the public or the decision-makers-it's too far off. If $\mathrm{NIH}$ would support successful models and provide toolkits, more of this type of activity would occur. A way to do that could be through the NIH Neuroscience Blueprint.

The NIH Neuroscience Blueprint could recognize, reinforce, and reward centers of excellence for collaboration and engagement across the country. Then others would aspire to do the same thing and build local and regional capacity for public engagement. Right now there are no incentives for this. There is truth in rewarding behavior you want to see more of. The Blueprint is meant to address "crosscutting initiatives." It has successfully accomplished this in other core areas deemed necessary for neuroscience research advancement. This would create powerful networks: to both (1) build internal constituencies through collaboration and (2) external constituencies of support (numbers of voters, donors, patients, and advocates). There would be tens of thousands of people 
connected in an ongoing way. The American Brain Coalition is an excellent model for collaborative advocacy for organizations. If Neuroscience Centers for Public Engagement were supported and integrated through the Blueprint, then ongoing support for funding neuroscience research would not even be a question.

This could be a new type of Grand Challenge for the NIH Neuroscience Blueprint, creating a best practice approach to public engagement-a "Brain Trust" of knowledge of effective strategies. It is a chance to change the culture from one of isolation to one of involvement and connection, using the brain as the most powerful metaphor. A national network of such centers would be established, all with constituencies of engagement and influence. The National Cancer Institute has already accomplished this through its National Association of Cancer Development Officers/Public Affairs Network (NACCDOPAN) and its linkage with the American Cancer Society. The sophistication of the public engagement around cancer has proven itself in the resulting vast support for cancer research. There are twice as many brainrelated problems as there are cancer and heart problems, put together. Brain problems cost society twice as much, yet research funding is a mere half of cancer research funding. Neuroscience public engagement is disconnected and not supported at the local and regional level. A Brain Trust of public engagement activities and expertise would help correct this imbalance.

To quote Alan Leshner in his recent "Seize the Neuroscience Moment" editorial, neuroscience "remains a small science field. . .other fields have successfully come together to participate in and support large projects that subsequently garnered substantial public and policy-maker support and funding. The new brain initiatives have great potential to accelerate progress in all of neuroscience. They should be fully embraced." I will add that large constituencies embrace at a large scale.

Finally, this idea fits the principles of the BRAIN Initiative. It would help build momentum for more funding. And it fits President Obama's style of community organizing, giving the Initiative a groundswell of "foot soldiers." The story then becomes more than scientists worried about losing their jobs; it's about a country becoming excited and mobilized about research that makes a difference for everyone.

"Public sentiment is everything. With public sentiment, nothing can fail; without it, nothing can succeed."

—President Abraham Lincoln

For more information on OHSU's Brain Institute's Brain Awareness program, go to http://www.oregonbrains.org.

\section{References}

Collins F (2013) One mind for research (personal communication)

Dreifus C (2014) Alan Alda, spokesman for science. In: New York Times. New York, New York.

Hosler L (2013) http://www.aaas.org/news/culture-science-engagement-becoming-less-formal-experts-agree. Accessed on 09/09/2014.

Leshner AI (2003) Public engagement with science. Science 299:977. CrossRef Medline

Wooley M (2014a) American say scientists aren't communicating the impact of science. In: Letter\#132. Alexandria. VA.

Wooley M (2014b) http://researchamerica.wordpress.com/2014/07/17/a-weekly-advocacymessage-from-mary-woolley-will-researchhave-every-opportunity-to-conqueralzheimers/. Accessed on 9/9/2014. 